\title{
A comparison of trends in population size and life history features of Atlantic salmon (Salmo salar) and anadromous and non-anadromous Brown trout (Salmo trutta) in a single catchment over 116 years
}

\author{
Colin E. Adams $(\mathbb{D} \cdot$ Hannele M. Honkanen · Ellen Bryson • Isabel E. Moore • \\ Malcolm MacCormick • Jennifer A. Dodd
}

Received: 10 March 2021 / Revised: 25 October 2021/ Accepted: 5 November 2021/Published online: 27 November 2021

(C) The Author(s) 2021

\begin{abstract}
We use a long time series of catch abundance from a recreational fishery over 116 years to look for population trends in Atlantic salmon, and anadromous (sea trout) and non-anadromous (brown) trout for a single catchment, Loch Lomond, west central Scotland. Year strongly predicted variation in catches but catch effort did not meaningfully increase explained variation. Salmon showed periods of increasing and decreasing trends, for sea trout and brown trout there was an overall declining trend. Since 1952, Lomond salmon population trends differed from both wider Scotland and southern Europe, indicating that the Lomond population is partially buffered from
\end{abstract}

Handling editor: Pauliina Louhi.

Supplementary Information The online version contains supplementary material available at https://doi.org/10.1007/ s10750-021-04751-2.

C. E. Adams $(\bowtie) \cdot$ H. M. Honkanen .

E. Bryson · I. E. Moore

The Scottish Centre for Ecology \& the Natural Environment, IBAHCM, University of Glasgow, Rowardennan, Glasgow G63 0AW, UK

e-mail: colin.adams@glasgow.ac.uk

M. MacCormick

The Loch Lomond Fisheries Trust, 2 Stewart St, Milngavie, Glasgow G62 6BW, UK

J. A. Dodd

Animal and Plant Sciences Group, Edinburgh Napier University, Sighthill Campus, Edinburgh EH11 4BN, UK drivers of change in salmon populations more widely. In contrast Lomond sea trout showed a similar declining trend to that of populations from the wider west of Scotland over this period. The Lomond populations showed some evidence of shorter-term cycling patterns; the drivers for which are unknown. Body size in salmon and sea trout declined but increased in brown trout; salmon returned to freshwater later, and the relative proportion of all caught trout that were anadromous increased across the time series. This study shows a long and protracted period of fundamental change to populations of these two species over 116 years.

Keywords Population decline - Atlantic salmon · Brown trout $\cdot$ Sea trout $\cdot$ Life history change

\section{Introduction}

There is compelling evidence that populations of Atlantic salmon (Salmo salar Linnaeus, 1758) have been declining over time (Condron et al., 2005). National fisheries data collated by the International Council for the Exploration of the Sea (ICES) Working Group on North Atlantic salmon (WGNAS) shows a marked decline in the reported salmon catches across all 15 reporting countries in both the west and east of the North Atlantic by 2016 to around $12 \%$ of that in the early 1960's (Fig. 1a) (ICES, 2017). 

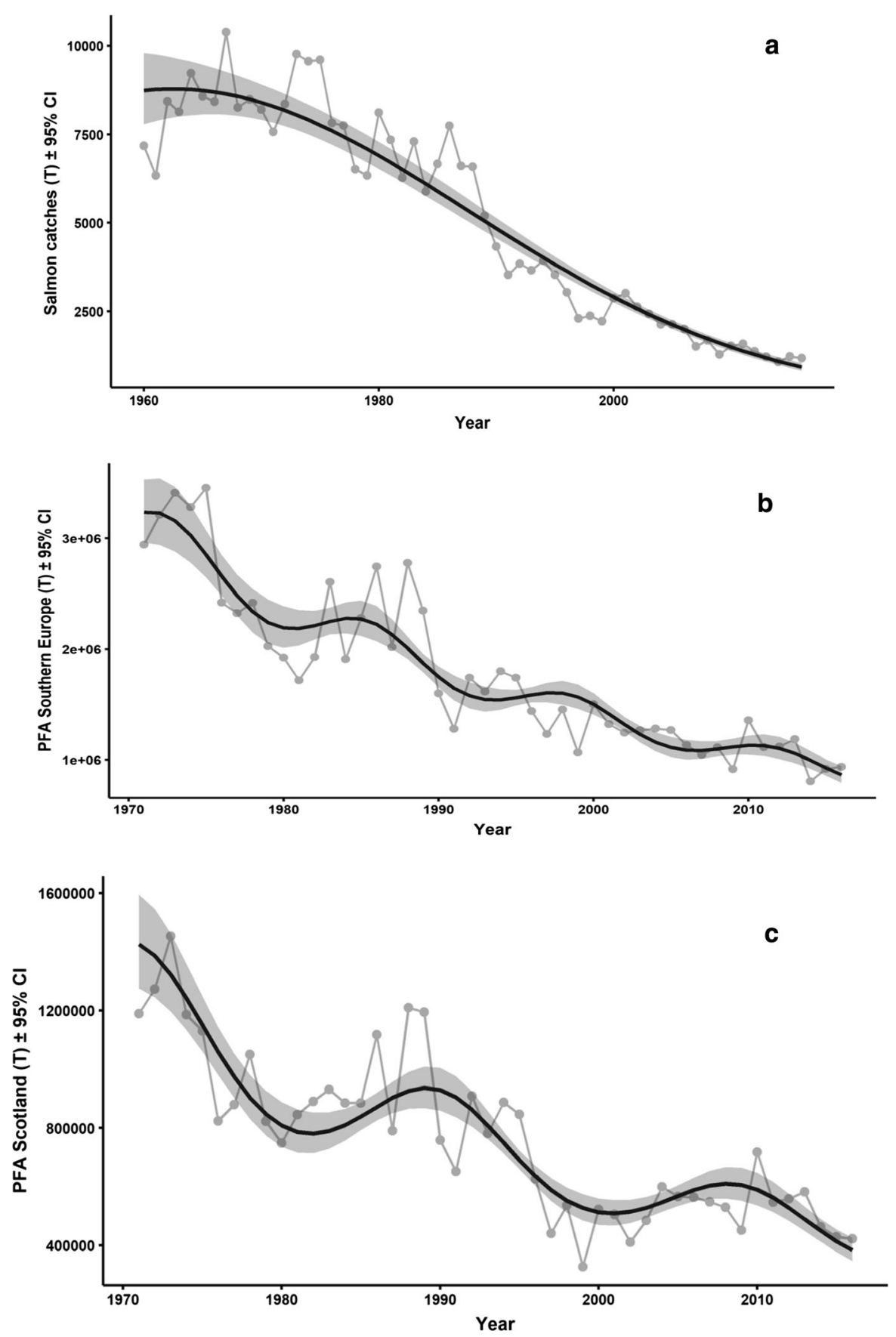

The decline is not simply a reduction in catch effort. Estimates of population sizes independent of capture by fisheries (pre-fisheries abundance (PFA)) for northern populations of the east north Atlantic (Russia, Finland, Norway and north and east Iceland) showed declines of $49 \%$ in salmon that spent one winter at sea
(1 SW salmon) between 1971 and 2010, and 54\% in fish that spent more than one winter at sea (multi-sea winter (MSW) salmon) between 1971 and 2009 (Chaput, 2012). In rivers further south in the eastern North Atlantic (Scotland, Northern Ireland, England \& Wales (combined), Ireland, France and south and west 
4Fig. 1 Changes in the Atlantic salmon population metrics over different geographical areas. Grey points and the solid line are the uncorrected annual catch data on year; solid dark line is the fitted polynomial model with grey shading the $95 \%$ CI, (data source ICES WGNAS 2017). a The change in national reported catches (in tonnes) across all ICES WGNAS reporting countries (Canada, USA, Norway, Russia, Iceland, Sweden, Denmark, Finland, Ireland, England, Wales, Scotland, Northern Ireland, France and Spain) between 1960 and 2016; Salmon catches declined significantly $\left(\right.$ LRstat $\left._{(56,54)}=168.6, P<0.001\right)$; over the period. The best model describing the change in salmon catches included a first and second order polynomial of year and accounted for $91.8 \%$ of the variation $\left(R^{2}=0.918\right)$ (Online resource Table S2 Model 1). b Pre-fishery abundance (PFA) estimates (fish number) across ICES WGNAS reporting countries for southern Europe (Scotland, Northern Ireland, England \& Wales (combined), Ireland, France and south and west Iceland) between 1972 and 2016; PFA declined significantly $\left(\operatorname{LRstat}_{(45,43)}=93.99, P<0.001\right)$ over the study period. The best model describing the change in pre-fishery abundance was a first order polynomial including a harmonic function with a wavelength of 13 years. This model year accounted for $86.1 \%$ of the variation in PFA $\left(R^{2}=0.861\right)$ (Online resource Table S2 Model 2a). c PFA estimates for Atlantic salmon for Scotland between 1960 and 2016; PFA declined significantly (LRs$\left.\operatorname{tat}_{(45,43)}=74.66, P<0.001\right)$ over the period. The best model describing the change in pre-fishery abundance was a first order polynomial including a harmonic function with a wavelength of 19 years. Year accounted for $79.1 \%$ of the variation in PFA $\left(R^{2}=0.791\right)($ Online resource Table S2 Model 2b)

Iceland) there is a similar and clear pattern of decline of around $84 \%$ over this period (Fig. 1b). This is consistent with the findings of Chaput (2012) who showed for this same geographic area that $1 \mathrm{SW}$ salmon numbers declined $66 \%$ between 1971 and 2010 and MSW numbers by $81 \%$ between 1971 and 2009.

There is evidence that this decline is solely not only the effect of extirpation of Atlantic salmon from a few countries reducing the abundance over broader geographic areas. The number of salmon returning to Norwegian home waters is now around half of the level of 30 years ago (Forseth et al., 2017). In Scotland, Youngson et al. (2002) used catch data from the commercial and recreational rod and line fisheries to show a decline amongst MSW salmon that migrated into freshwater early in the year before spawning (in late autumn/winter) between 1952 and 1997. National data from Scotland, combining all age classes, shows a steep decline in the PFA estimates of all Scottish salmon populations (of all sea age classes) combined (Fig. 1c). Year accounts for $79.1 \%$ of the variation in
PFA and a fitted model indicates a decline of around $72 \%$ of total salmon PFA between 1971 and 2016.

The status of anadromous Salmo trutta Linnaeus 1758 populations (hereafter referred to as sea trout), has been less well studied than Atlantic salmon, but what is known suggests a more complex pattern of population change. Hojesjo et al. (2017) reported a three-fold increase in sea trout smolt production across Denmark between the 1980's and 2000's and a similar increase in the River Hogsvadson, Sweden between 1980 and 2014. In England and Wales, returning migrant sea trout increased in the rivers Dee and Fowey between the 1990's and 2010's (Davidson et al., 2017) and in catches from six rivers in the north east of England over a similar period (Evans \& Harris, 2017). In contrast, catches (from all methods) in southern Norway rivers showed declines of between 22 and $77 \%$ over the period from the 1990's to the 2010's (Hojesjo et al., 2017). Similarly, 14 rivers in the north west of England showed decreases in catches (Evans \& Harris, 2017).

There is much less known about the status of the non-anadromous component of Salmo trutta (hereafter referred to as brown trout for convenience). There are no national or internationally collated population data; however, there are some river specific studies. LobónCerviá (2007), for example determined brown trout recruitment in the River Esva, Spain and showed considerable temporal stability between 1986 and 2006. Palm et al. (2003) estimated effective population size in two populations over 20 years showing that they were relatively stable over time. Similarly a non-native population of brown trout in the USA, examined between 1985 and 2011, showed no directional change in population size with time (Grossman et al., 2017). Elliot (1987) showed relatively high year-on-year fluctuations in recruitment in the brown trout population in Wilfin Beck, England, but could find no evidence of consistent patterns of change with time.

An understanding of long-term trends is essential as a management tool for exploited and high conservation value species (Clarke, 2010). One of the difficulties in determining long-term trends is separating shorter-term population fluctuations from the longer trends, as the former can mask the latter (Townsend, 1989; Shelton \& Mangel, 2011). Fish population size changes are a particular problem in this regard, as they frequently exhibit short temporal scale fluctuations of 
a magnitude that can mask longer term trends (see for examples Townsend, 1989; Campana, 1996; Karjalainen et al., 2000; Thompson \& Mapstone, 2002). One approach through which long-term trends may become apparent is using datasets of a temporal coverage that are long, relative to the period of shortterm fluctuations (Clarke, 2010).

Here we use a very long-term dataset spanning 116 years from Loch Lomond, west central Scotland, as well as shorter time series data covering different geographic areas to address questions relating to population trends in two salmonid species and two life history types of one species over time. Specifically, we test the following eight null hypotheses:

1. Rod catches of Atlantic salmon, sea trout and brown trout in Loch Lomond have not changed over time.

2. The pattern of change in Atlantic salmon in Loch Lomond mirrors that of populations from across Scotland and the wider eastern Atlantic.

3. The pattern of change in Loch Lomond catches of sea trout mirrors change from populations more widely in Scotland.

4. The pattern of catch change of salmon, sea trout and brown trout in Loch Lomond is the same for each species/life history.

5. Angling catch effort has no significant effect on estimates of population change.

6. There has been no change in body mass of fish captured by rod and line in Loch Lomond over time.

7. The relative proportion of the two life history strategies in Salmo trutta (anadromy and nonanadromy) in catches does not change over time

8. The seasonal pattern of catches of salmon sea and brown trout has not changed with time.

\section{Methods}

\section{Loch Lomond and its fisheries}

The Loch Lomond catchment $\left(56^{\circ} 06^{\prime} \mathrm{N} 004^{\circ} 37^{\prime} \mathrm{W}\right)$ in west central Scotland is a relatively small catchment $\left(781 \mathrm{~km}^{2}\right)$ dominated by an oligotrophic lake (Loch Lomond, $71 \mathrm{~km}^{2}$ ) with a single, short (12 km) efferent river, the River Leven, which discharges into an estuary, the Firth of Clyde and hence westward into the North Channel which links the Irish Sea with the eastern Atlantic Ocean.

Recreational fishing for salmon and trout has been practiced in the area since at least the mid- seventeenth century (Franck, 1694) but became more formalised with the formation of the Loch Lomond Angling Improvement Association (LLAIA) sometime around 1900 (Maitland, 1972). This angling club continues to manage the angling on Loch Lomond and most of its tributaries and its members have access to almost all of the fishing areas in the catchment.

There are a number of afferent rivers and streams running into the main lake, the largest of which are the Endrick Water to the south east, the River Fruin to the west and the River Falloch in the north. These rivers, plus the efferent River Leven all support salmonid populations and all are subject to a recreational rod fishery (Maitland, 1972).

The Salmon \& Freshwater Fisheries (Protection) (Scotland) Act 1951 requires all fisheries to report catches of Atlantic salmon and sea trout. These data are currently collected nationally by Marine Scotland Science (Youngson et al., 2002; Marine Scotland Science, 2019). However, the LLAIA have been recording recreational angling catch data for their own purposes since 1903 (Maitland, 1972). In addition to simple numbers of fish caught, and unlike the national government catch dataset, the LLAIA also records the number of anglers who are members of the club, allowing for a measure of effort. Catch weights have also been recorded sporadically for some years.

\section{Dataset}

Although its utility has been questioned (see for example Shearer, 1988), a significant number of studies have used recreational angling catch returns as a measure of the change in fish population size. Youngson et al. (2002) and Vøllestad et al. (2009) both used rod catch data without correction for catch effort for salmonid species to demonstrate consistent patterns of temporal change. Beaumont et al. (1991) demonstrated that angling catches uncorrected for effort were a good predictor of Atlantic salmon abundance in a southern English river. Crozier and Kennedy (2001) similarly showed that angling catches were a good predictor of fish numbers derived from a fish counter in a Northern Irish river. Smith and colleagues (Smith, 2000; Smith et al., 2000) 
Table 1 The time series, geographic coverage, sample size and missing years for each variable in the data-set analysed in the study presented here

\begin{tabular}{|c|c|c|c|c|}
\hline Dataset & $\begin{array}{l}\text { Time } \\
\text { series }\end{array}$ & Geographic coverage & $N$ (years) & Missing years \\
\hline $\begin{array}{l}\text { Atlantic salmon } \\
\text { catches }\end{array}$ & $1903-2018$ & Loch Lomond (lake) only & 78 & $\begin{array}{l}\text { 1931-1952 1954, 1957-1961, 1964-1966, } \\
1969-1976\end{array}$ \\
\hline Sea trout catches & 1903-2018 & Loch Lomond (lake) only & 78 & $\begin{array}{l}\text { 1931-1952 1954, 1957-1961, 1964-1966, } \\
\text { 1969-1976 }\end{array}$ \\
\hline Brown trout catches & 1903-1994 & Loch Lomond (lake) only & 54 & $\begin{array}{l}\text { 1931-1952 1954, 1957-1961, 1964-1966, } \\
\text { 1969-1976 }\end{array}$ \\
\hline Atlantic salmon mass & $1952-2017$ & $\begin{array}{l}\text { Whole Loch Lomond } \\
\text { catchment }\end{array}$ & 49 & 1954, 1957-1961, 1964-1966, 1969-1976 \\
\hline Sea trout mass & $1952-2017$ & $\begin{array}{l}\text { Whole Loch Lomond } \\
\text { catchment }\end{array}$ & 49 & 1954, 1957-1961, 1964-1966, 1969-1976 \\
\hline Brown trout mass & $1952-2017$ & $\begin{array}{l}\text { Whole Loch Lomond } \\
\text { catchment }\end{array}$ & 49 & 1954, 1957-1961, 1964-1966, 1969-1976 \\
\hline
\end{tabular}

successfully used rod catch data corrected for angling effort to estimate abundances of rainbow trout $(\mathrm{On}$ corhynchus mykiss (Walbaum, 1792)). Studies using rod catches from lakes are fewer; however, angler catches have been shown to be a reliable index of population size change when compared against other techniques for some species (Elliot and Fletcher, 2001; Wilfield et al., 2008). Fish catches from the rod fishery combined with other fishery data were used as indices of population size trends in Atlantic salmon in studies of the effects of climate variation in North America (Friedland et al., 1993) and in Europe (Boylan \& Adams, 2006). Similarly angling catch per unit effort was used as measure of population size in a study to examine long-term drivers of change in a population of Atlantic salmon in Spain (Almodóvar et al., 2019).

The principal long-term dataset examined here comprises catch returns for salmon, sea trout and brown trout from Loch Lomond (that is, catches only from the lake and not the efferent or afferent rivers). For salmon and sea trout, the data extend over the 116 years between 1903 and 2018; for brown trout for 92 years between 1903 and 1994. However, there are missing data for 38 years, most notable being from between the years 1931 and 1952 (Table 1). Until very recently (around 2015) a very high proportion of fish caught in the recreational fishery were killed; after 2015 the number of fish caught and released increased.

Data on the number of full members of the LLAIA has been collected (albeit with data gaps) since 1903, providing a measure of angling effort. Although not a direct measure of the actual time spent in fish capture, the number of active membership subscriptions is likely a consistent measure of effort over time. Missing data in the membership were filled by interpolation from the period before and after a gap assuming a proportionate change over time.

Fish catches over time in Loch Lomond were compared with broader geographic regions. For salmon, published annual PFA estimates, comprising the output of a Bayesian abundance forecast model that estimates of the population size independent of catches (ICES, 2019), for southern European populations (comprising the combined annual national estimates for France, Iceland, Ireland, England, Wales, Northern Ireland and Scotland) and for Scottish populations were used (ICES, 2019). Sea trout catch change in Loch Lomond was compared with national statistics for 76 reporting areas that comprise rivers draining to the west coast Scotland, drawn from the Scottish Salmon and Sea Trout Fishery Statistics dataset comprising the statutory reported catches of Atlantic salmon and sea trout in Scotland, currently collected nationally by Marine Scotland Science (Youngson et al., 2002; Marine Scotland Science, 2019). For comparison we used catch numbers captured by all methods, including recreational angling catches and catches by commercial inshore and in river netting where these exist (further details in Moore, 2020). 
Fish mass has been recorded for fish over a 66 year period from between 1952 and 2017, from the fishery across the whole Loch Lomond catchment (that is, including afferent and efferent rivers) however there are 17 years without data (Table 1). Mass was recorded each year as the total mass of a defined number of fish of each type and thus a single mean mass figure could be derived for each year. For salmon, there was no discrimination made between one-sea winter fish and multi-sea winter fish, thus mean mass represents an average of multiple sea age classes.

\section{Data analysis}

Population index change was modelled using a combination of techniques to describe linear, nonlinear and harmonic trends. Initial exploration of the data revealed two sources of patterning within the time series; long-term trends and in some time series, shortterm fluctuations. Long-term trends, which described the overall change in the index of population size across the time period, were described using functions that included both linear and non-linear elements using both a first and second order polynomial with calendar year as a covariate. The second order polynomial allowed the identification of possible mid-series maxima and minima. To account for the possibility that there may be some autocorrelation in indices of population change across the time series and to describe and quantify any short-term periodic fluctuations in the datasets, a three-step process was conducted. Firstly, an initial exploratory model comprising first and second order polynomials was constructed. Secondly, residuals of this initial model were tested for any significant time lagged autocorrelation indicative of shorter-term periodic fluctuations. Where a significant time lag autocorrelation was detected, the identified time lag was used to create a harmonic function to include in the final model (step 3). These shorter-term fluctuations were described using a harmonic function of the form $(\sin (2 * \pi *$ (year wavelength)/wavelength) where the wavelength was defined from the lag in years derived from of the autocorrelation function in step 2 for that dataset.

All maximum initial models used the measure of population size as the response variable, with calendar year as a covariate. Calendar year was included as both a first and second order polynomial and, if significant autocorrelation in that dataset was detected, a harmonic function, described above, was also included. Species and/or life history variant and geographic area, were included as factors. Models included an interaction term to account for differential fish group or area-specific patterns of long-term change. The magnitude of any change over time is simply described by the change in the population size index, derived from the fitted function over that time period.

The best fitting models were selected based on sequential removal of non-significant terms and significance testing between competing models. Overall, the significance of the best supported model is reported as the likelihood ratio, deviance or $F$ statistic (LRstat, Deviance or Fstat) describing the difference in fit of the best supported model compared against a null model. Variation described by the best model is reported as an $R^{2}$ value, calculated as the squared correlation between the fitted and observed values from the best model. All population size index data, including catch data, were analysed using a negative binomial distribution (to account for overdispersion). This modelling approach has the disadvantage over more descriptive modelling techniques, such as a generalized additive model (GAM), as it does not allow for a fitted model to respond to very short-term trends in the dataset in a way that, for example, a GAM does. The adopted approach does provide two major advantages. Firstly, the method provides a robust statistical comparison between time series, in the form of statistical interactions, whilst testing and accounting for any autocorrelation within the dataset, albeit at the expense of marginally greater unexplained residual variation. Secondly, the approach provides for a more precise algebraic description of the fitted model, thus providing the potential to be easily replicated and compared with other datasets. All models were checked for overdispersion (where appropriate), collinearity between polynomial and linear predictors and homoscedastic residuals.

To investigate differences in trends between fish species and life history variant and areas, relative measures of population indices were used to take account of differences in the magnitudes of the population indices between fish groups and areas. This comprised expressing the annual catch or PFA as a proportion of the total overall years.

To investigate seasonal change in catches in Loch Lomond, the monthly proportions of fish caught in a 
calendar year between 1952 and 2018 were grouped into seasons (following Shearer, 1990) (spring $=\mathrm{Fe}$ bruary to April; early summer = May to June; late summer = July to August; autumn $=$ September to October). Proportional data were analysed using a quasi-binomial distribution. To analyse possible change in fish mass, these data were standardised ( $z$ score $=(x-\mu) / \sigma)$ and analysed using a Gaussian distribution.

To examine changes in the ratio of anadromous sea trout and non-anadromous brown trout, a Pearson's correlation was used to test for an effect of year on the ratio of sea trout to brown trout catch determined each year.

To test for an effect of angling effort on catch from Loch Lomond, the number of members of the angling club each year was included as an explanatory variable to the best models explaining the change in salmon, sea trout and brown trout catches over time. The effects of angling effort were reported as the change in variation explained, explicitly as the difference between the $\mathrm{R}^{2}$ of the paired models (with and without the measure of angling effort). The two output values for each year derived from the two models were plotted against each other and compared with unity to determine how far predicted values from models, including and excluding a measure of angling effort, deviated from a one-to-one relationship. Overlap between the $95 \%$ confidence interval (CI) and unity was assumed to be strong evidence that the relationships were not statistically different.

The effects of catch effort on predictions on longterm predictions of catch

Including the number of angling club members had different effects on the variation explained for each fish group (species and life history variant). For salmon, there was a negligible change to the total variation explained ( $R^{2}$ decreased by 0.0008 with the inclusion of the number of members compared with the same model that did not include this measure of effort) and all fitted values from the two models overlapped with unity. For sea trout the number of members added 5\% more explained variation but values overlapped with unity. For brown trout, club membership explained $16.2 \%$ more variation but all but only two of the 57 model estimates of catch did not overlap with unity (Online Resource Figure S1).
As a result, the angling catches from Loch Lomond were not adjusted for the measure of effort available, in the study reported further here. This also allowed for a more comprehensive comparison with other datasets for which there was no measure of effort available.

All analyses were conducted in R ( R Development Core Team, 2017).

\section{Results}

Population trends over time

The average number of anglers fishing in the Loch Lomond catchment between 1903 and 2018 was $621 \pm 188$ (mean \pm SD). They caught on average a total of 131 salmon, 483 sea trout and 284 brown trout each year from Loch Lomond (lake only) over this period. The average catch rate per 100 anglers was 23 salmon, 97 sea trout and 79 brown trout per year (Online Resource Table S1). However, there is a very considerable range around these means over this period (Online Resource Table S1); the highest and lowest catches of salmon being in 1925 and 1905, respectively; for sea trout the highest and lowest catches were in 1912 and 1994, respectively; for brown trout in 1907 and 1955, respectively.

The number of salmon caught (all ages and sizes, all months combined) changed with year between 1903 and 2018 (Fig. 2a) and showed both long and shorterterm fluctuations with time. Change across the time series was best described by a first and second order polynomial function and a harmonic function with a wavelength of 32 years; this model explained $37 \%$ of variation in catches. The fitted model apparently did not represent actual catches in the first few years of the data series well (Fig. 2a). However, a test for homoscedasticity showed no relationship between model residuals and year. Despite this, it is clear that change in catch across the whole time period was relatively small but a significant second order polynomial term and the fitted model shape indicate that catches were markedly higher during the middle period of the time series. The pattern of change is thus relatively complex, but model predicted catches were relatively low around the beginning of the data series (20-30 fish) rose into the mid 1920's where model predicted catches exceeded 200 and some years 

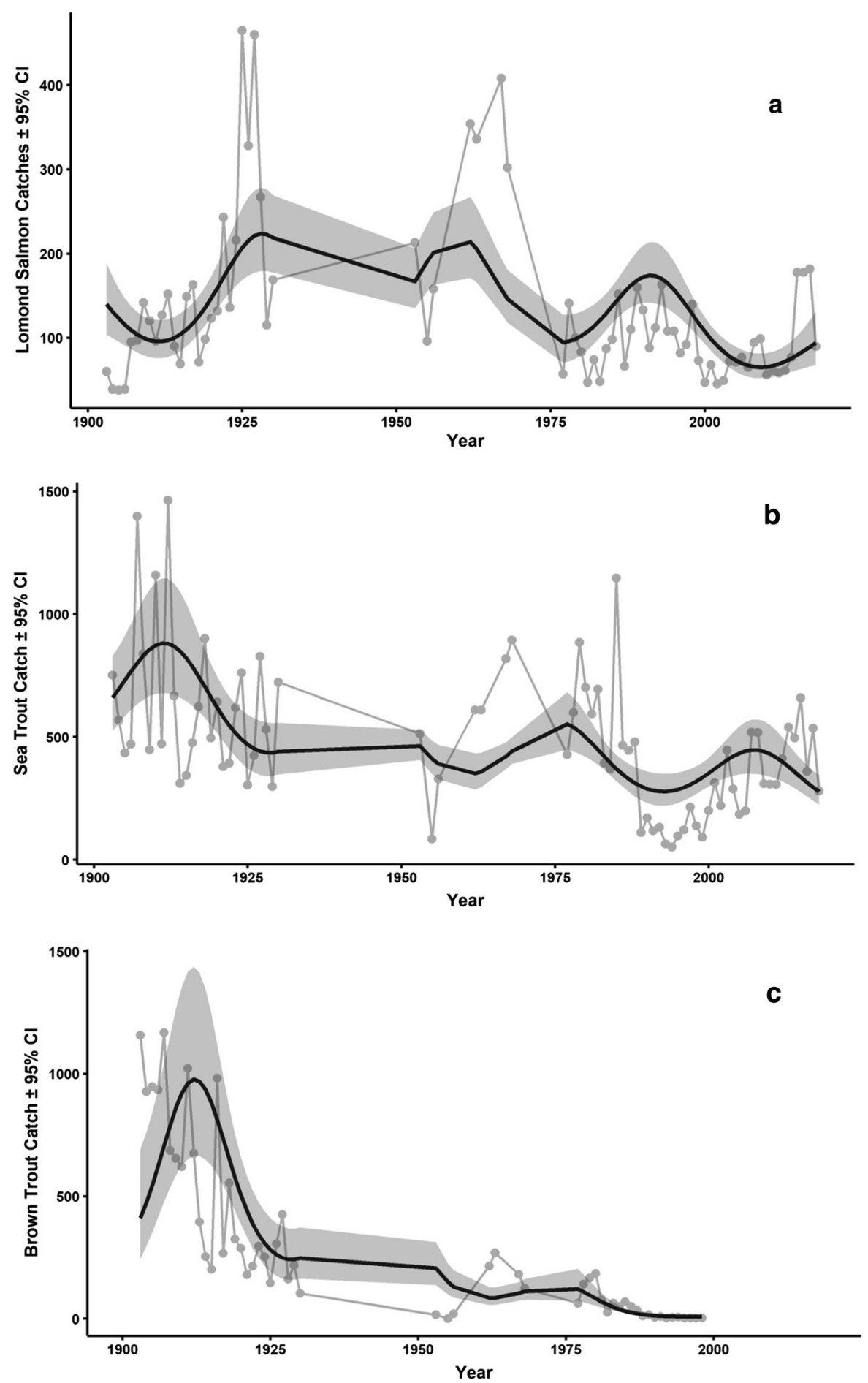
4Fig. 2 Catches of salmon, sea trout and brown trout from Loch Lomond over the period 1903-2018. Grey points and the solid line are the annual catch data on year uncorrected for fishing effort; solid dark line is the fitted polynomial model with grey shading the $95 \%$ CI. a Salmon catches (fish number) (all age classes combined and uncorrected for catch effort) changed significantly over the study period $\left(\operatorname{LRstat}_{(76.73)}=37.67\right.$, $P<0.001)$. The best model describing the change in salmon catches included a first and second order polynomial on year and a harmonic function with a wavelength of 32 years. The first order $(P=0.070)$ and the second order (lower at $P=0.068$ ) were significant, indicating that, across the whole time series, the long-term change was small but that higher catches were recorded in the middle of the study time period. Overall the model described $36.8 \%$ of variation in catch $\left(R^{2}=0.368\right)$ (Online resource Table S2 Model 3). b Sea trout catches from Loch Lomond (all ages classes combined). Sea trout catches changed significantly $\left(\operatorname{LRstat}_{(76.74)}=24.32, P<0.001\right)$ over the study period. The best model describing the change in sea trout catches included a first order polynomial and a harmonic function with a wavelength of 32 years. The coefficient of the year estimate was negative, indicating a decline in sea trout catches over the study period. The model described $26.2 \%$ of the variation $\left(R^{2}=0.262\right)$ (Online resource Table S2 Model 6). c Catches of brown trout from Loch Lomond from between 1903 and 1998. Catches generally declined significantly over the period $\left(\right.$ LRstat $\left._{(56.53)}=80.44, P<0.001\right)$. The model best describing the change in brown trout catches included a first and second order polynomial and a harmonic function with a wavelength of 32 years and explained $52.1 \%$ of the variation $\left(R^{2}=0.521\right)$. The coefficients of the year in second polynomial and the harmonic functions were negative, indicating a general decline in brown trout catches in Loch Lomond over the study period (Online Resource Table S2 Model 8)

returned numbers in excess of 400 salmon. Numbers remained high into the 1960 s before declining in the mid 1970's, rising again at the end of the 1980's/early 1990's before declining again in the late 2000's (although there is some evidence of catches that are moderately high in the context of the long-term pattern around 2014-17 (Fig. 2a)).

Thus, although the time periods differ, the pattern of change in Atlantic salmon catches from Loch Lomond appear to differ from the trends of the proportional change in PFA from southern Europe more widely and Scotland as a whole (Fig. 3). To test this, the trends in the proportional catch data for Loch Lomond, were compared from the time series (from 1977 to 2016) over which there are common data with the proportional change in PFA for the whole of Scotland and for southern Europe (populations from France, Iceland, Ireland, England, Wales, Northern Ireland and Scotland) (ICES, 2019). There were highly significant differences in the patterns of the proportionate change between these three areas (Deviance $_{(119,113)}=0.165, P<0.001$; Fig. 3a; Online Resources Table S2 Model 4). Pairwise post hoc tests showed no significant difference in population size estimates with time between southern Europe populations and Scotland $(P=0.77)$ but there was a strong difference between Lomond and both Scotland $(P<0.001)$ and southern Europe $(P<0.001)$ (Online Resources Table S2 Model 4). Over this period, the relative abundance of salmon from south Europe (Fig. 3b) and Scottish populations (Fig. 3c) declines markedly, whereas in contrast, the Loch Lomond population (Fig. 3d) showed relatively little directional change.

The number of sea trout captured in the recreational fishery on Loch Lomond changed with year between 1903 and $2018(P<0.001)$ (Fig. 2b). Change in sea trout catches with year was best described by a first order polynomial and a harmonic function with a wavelength of 32 years (Online Resources Table S2 Model 6). This model accounted for $26 \%$ of variation in catch. The effect of year returned a highly significant $(P<0.001)$ and negative coefficient of year $(b=-0.007)$, with absolute catch numbers declining by approximately $64 \%$ over the study period (Fig. 2b). The number of sea trout reported captured by all methods from rivers draining to the west of Scotland between 1952 and 2018 also show clear evidence of relatively strong $(b=-0.018)$ and significant decline $\left(\operatorname{LRstat}_{(66.64)}=97.14, P<0.001\right.$; Fig. 4; Online Resources Table S2 Model 5). The model best describing the trends explained $75 \%$ of variation and comprised a first order polynomial with a harmonic function with a wavelength of 18 years (Online Resources Table S2 Model 5). The fitted model did not represent catches in the first few years of the data series well. However, a homoscedasticity test showed no relationship between model residuals and year. Despite this, it is clear that reported sea trout catches declined by ca. $62 \%$ over the time period of the study. Unsurprisingly year predicted proportionate catch for the populations from rivers draining to the west of Scotland and Loch Lomond from between 1952 and 2018 (Fig. 5a). This relationship was best described by a first order polynomial and a harmonic function with a wavelength of 32 years; however, there was no effect of geographic area (Lomond cf. west Scotland) indicating that the decline in catch was 
a

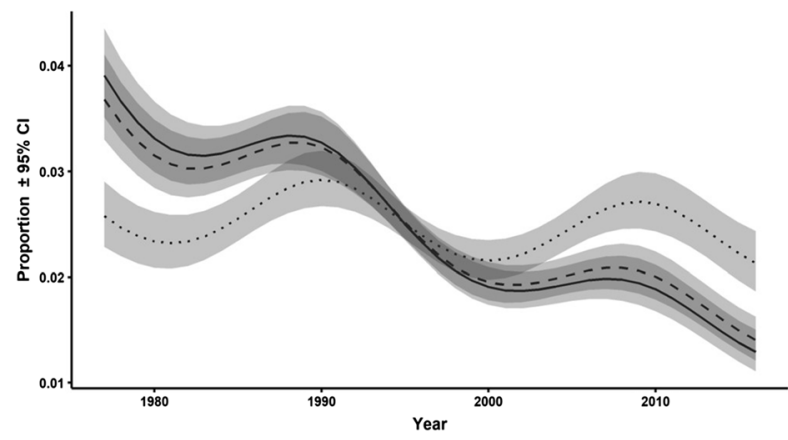

C

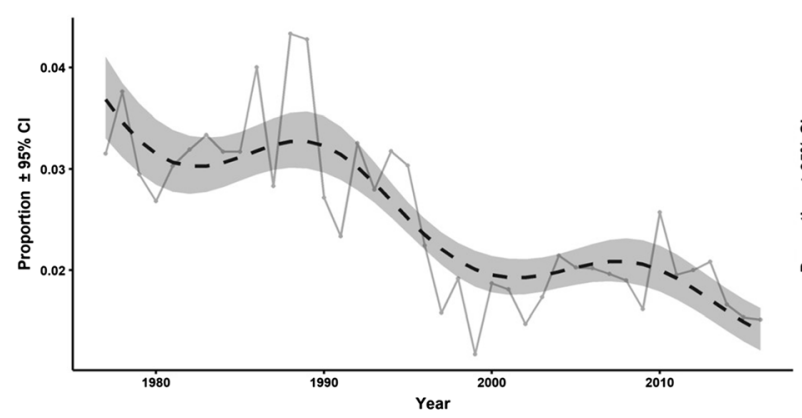

Fig. 3 The relative population size estimate (comprising the annual population size estimate expressed as a proportion of the estimate for all years) from between 1977 and 2016 for salmon from southern Europe (solid line), Scotland (dashed line) and Loch Lomond (dotted line). The grey solid lines are the annual catch data on year, uncorrected for angling effort; solid dark line is the fitted polynomial model with grey shading the $95 \% \mathrm{CI}$. a a

similar for Lomond and for the wider west of Scotland (Fig. 5b).

The number of brown trout reported caught in Loch Lomond also declined with year between 1903 and 1998 (Fig. 2c). The model best describing the change in brown trout catches included a first and second order polynomial and a harmonic function with a wavelength of 32 years $\left(\operatorname{LRstat}_{(56.53)}=80.44\right.$, $P<0.001)$ and explained $52.1 \%$ of the variation in catch (Online Resources Table S2 Model 8). The fitted model did not represent catches in the first few years of the data series well. However, there was no relationship between model residuals and year in a homoscedasticity test. Despite this, it is clear that the plot of catch with year (Fig. 2c) shows a steep decline in reported brown trout catches in Loch Lomond over the study period such that the catch of approximately 1000 brown trout reported annually at the beginning of

\section{b}

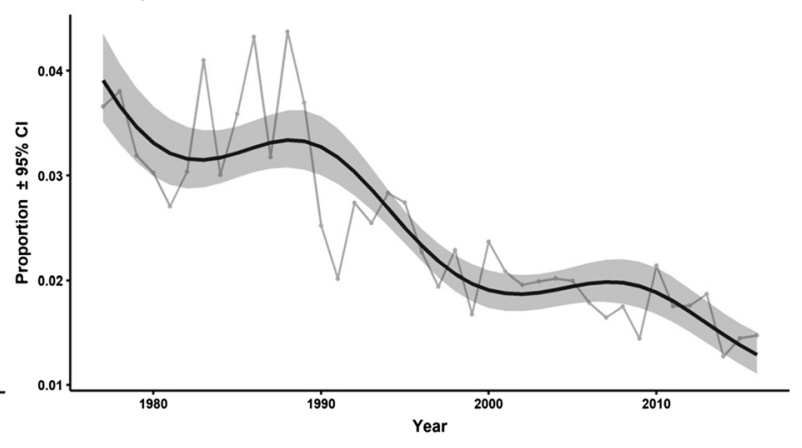

d



comparison of the regression lines for each area and the original data for: b southern Europe, c Scotland and d Loch Lomond (Online Resource Table S2 Model 4). Pairwise analysis showed no difference between southern Europe and Scotland, but the Lomond salmon change with year was significantly different from that of South Europe and Scotland

the dataset had declined to around 10 by the end of the time period. There are, unfortunately, no national data with which to compare the trends in Lomond brown trout catches.

Between fish groups population trends

To examine the patterns of change in catches between the two species and two life history stages, the relative proportional catches of all three groups were modelled. The proportion of each salmonid group changed significantly over time Deviance $_{(210,202)}=1.25$, $P<0.001$; Fig. 6). The best model describing the change in salmonid proportional catch with time included a first and second order polynomial, an interaction between year and fish group and two harmonic functions with a wavelength of 32 and 60 years (Online Resource Table S2 Model 9). The 


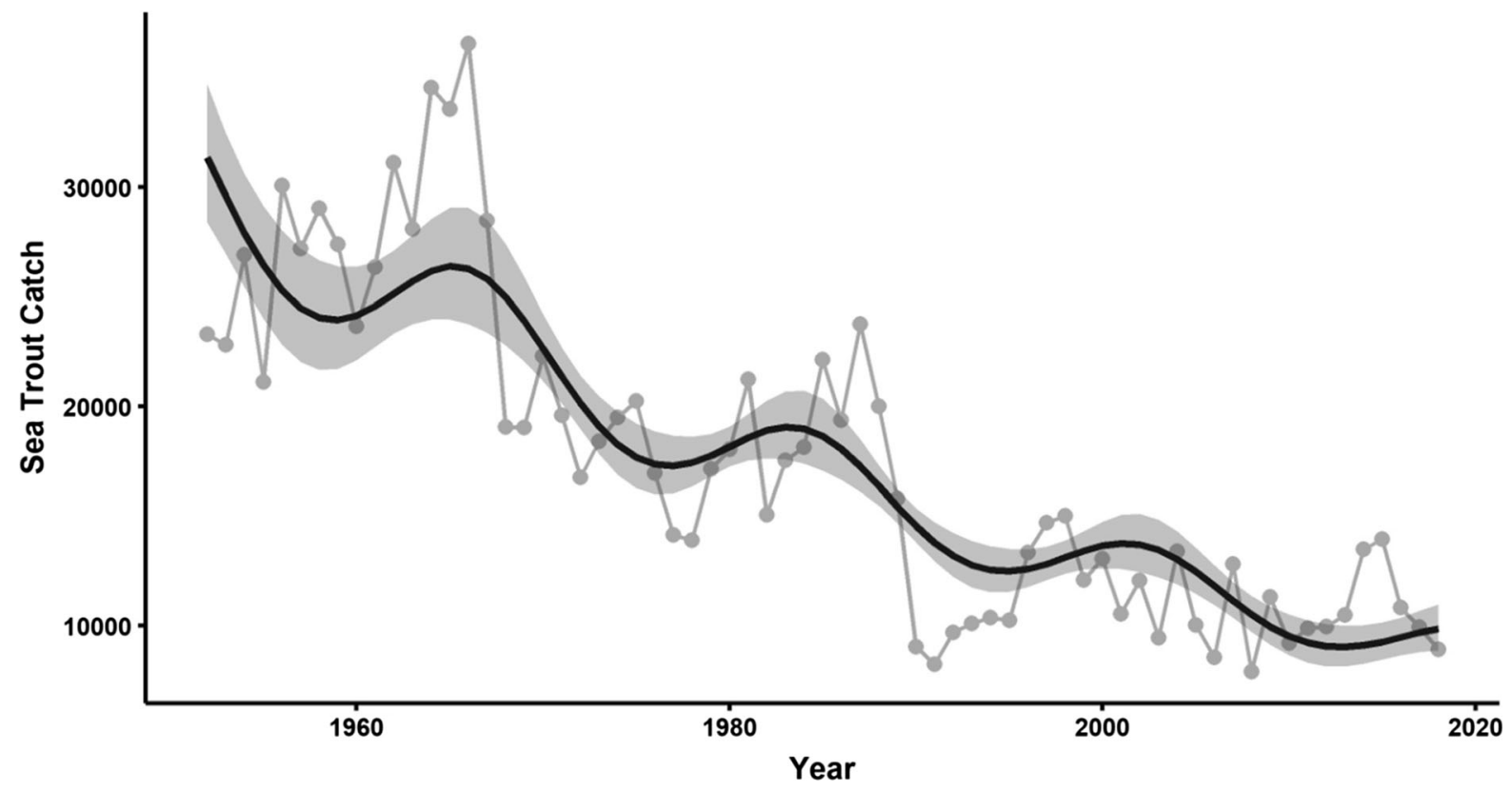

Fig. 4 Sea trout catches from the west coast of Scotland declined significantly $\quad\left(\right.$ LRstat $_{(66.64)}=97.14, \quad P<0.001$; $)$ between 1952 and 2018. The best model describing the change included Year and a harmonic function with a wavelength of 18 years and described $75.4 \%$ of the variation in the dataset

resulting model explained $62.2 \%$ of variation in proportional catch. Annual brown trout catches as a proportion of catches from all years combined (Fig. 6d), declined significantly over the study period, while salmon (Fig. 6b) and sea trout (Fig. 6c) displayed a fluctuating pattern of change. The change in brown trout proportional catch (Fig. 6a) was significantly greater (a more pronounced decline) than both salmon and sea trout (both $P<0.001$ ), but there was no difference in the patterns of change between salmon and sea trout $(P=0.47)$ (Online Resource Table S2 Model 9).

Body mass changes with time

The annual mean mass, (Online Resource Table S3) standardised for absolute differences in body size, of the salmonid fish groups caught by anglers on rod and line across the whole of the Loch Lomond catchment changed with time over the period 1952 to 2017 (Fig. 7a). The significant interaction between year and fish group indicated temporal change was different between fish groups. Both salmon (Fig. 7b) and sea trout (Fig. 7c) showed declining relative mass. The
$\left(R^{2}=0.754\right)($ Online resource Table S2 Model 5). Grey points and the solid line are the annual catch data on year (uncorrected for angling effort); solid dark line is the fitted polynomial model with grey shading the $95 \% \mathrm{CI}$

rate of change did not differ significantly between these two groups (Online Resource Table S2 Model 10). In contrast, brown trout (Fig. 7d) showed an increase in relative body mass over time and the pattern of change differed significantly from that of both salmon $(P=0.0003)$ and sea trout $(P=0.023)$. For salmon, the model estimated mean mass changed from $4.04 \mathrm{~kg}$ at the beginning of the dataset in 1952, to $3.09 \mathrm{~kg}$ by the end of the time series in 2017; for sea trout mass declined from $0.95 \mathrm{~kg}$ to $0.86 \mathrm{~kg}$ over the study period; and for brown trout it increased from $0.32 \mathrm{~kg}$ in 1952 to 0.62 in 1998 .

Changes in trout life history strategy over time

The proportion of sea trout in catches as a portion of all trout catches (brown and sea trout combined) was strong and positively predicted by year $(P<0.001)$ (Fig. 8; Online Resource Table S2 Model 11) indicating that the proportion of sea trout that comprised catches of this species increased over time between 1903 and 1998, from approximately $35 \%$ to in excess of $90 \%$. 

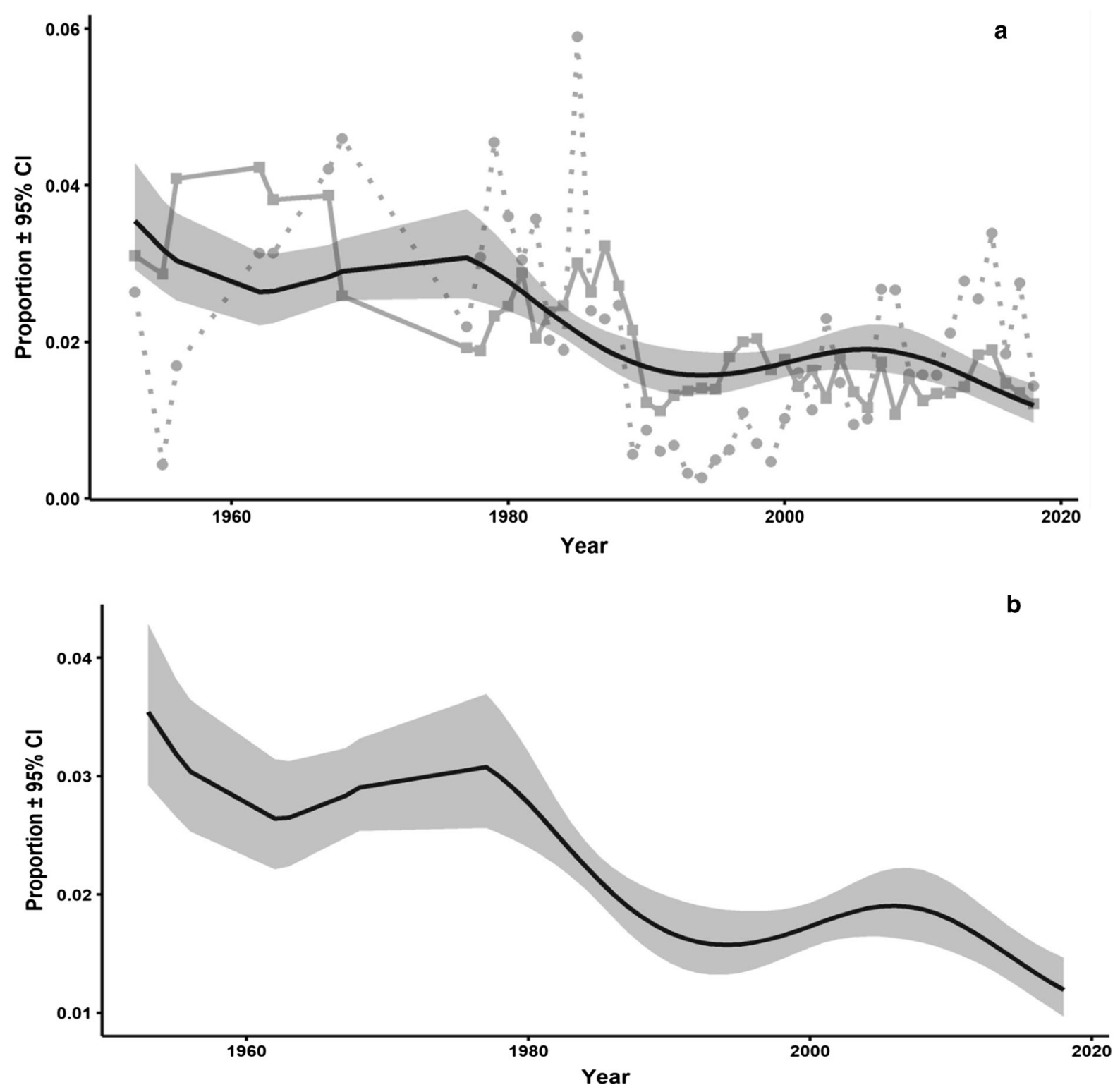

Fig. 5 a The annual proportional catches of sea trout caught in Loch Lomond (dotted grey line) and rivers draining to the west of Scotland (solid grey line) from 1952 to 2018. Both geographic areas showed significant declines in proportionate catches (Deviance $\left._{(97,95)}=0.1524, P<0.001\right)$. There was no statistical difference in the decline between the two areas; the best model describing change included a first order polynomial for Year and

Timing of catches

There was a marked effect of year on the seasonal catch of salmon in Loch Lomond over the 66 years between 1952 and 2018 (Fig. 9a). The model best describing the effect of year on the seasonal proportion a harmonic function with a wavelength of 32 years explained $28.2 \%$ of the variation in this dataset $\left(R^{2}=0.282\right)$; $\mathbf{b}$ the pooled model output of the combined points from Lomond and the west of Scotland, the solid dark line is the fitted polynomial model with grey shading the $95 \%$ CI. (Online Resource Table S2 Model 7)

of the total annual catch of salmon across the whole Loch Lomond catchment explained 59\% of the variation in catch and showed a strong interaction between season and year (Online Resource Table S2 Model 12.) The salmon caught in spring (February, March and April) as a portion of total catch declined 



Fig. 6 The proportional catches of the three salmonid groups (salmon, (solid line) sea trout (dashed line) and brown trout (dotted line)) from Loch Lomond (a), changed significantly over the time period (Deviance $_{(210,202)}=1.253, P<0.001$. The model best describing the change in salmonid proportion included a first and second order polynomial, an interaction between Year and Species and two harmonic functions with a wavelength of 32 and 60 years which explained $62.2 \%$ of the

significantly with year over this period $(P<0.0006$; Fig. 9b). In contrast there was no significant change in the relative proportion of the annual catch of salmon in any of the other three seasons (Fig. 9c, d and e; Online Resource Table S2 Model 12).

\section{Discussion}

The value of long time series datasets is their ability to detect change that is not evident in shorter time series data; they can distinguish rare, episodic events that exert disproportionate ecological effects, and they can help generate hypotheses around ecological change that can be tested (Hobbie et al., 2003; Dodds et al., 2012). They are particularly valuable for detecting long-term patterns in data which have very high temporal variability, where data of short duration are

variation in catch $\left(R^{2}=0.622\right)$. The proportion of brown trout (d) declined significantly faster over the study period than salmon (b) and sea trout (c) which did not differ from each other (Online resource Table S2 Model 9). Grey points and the solid grey line are the actual annual proportional catch data on year; dark line (solid, dashed and dotted) is the fitted polynomial model with grey shading the $95 \%$ CI

prone to large margins of error. They are also important where the dataset relates to managed species, where the high statistical resolution resulting from long time series data provides increased certainty around management action (Wolfe et al., 1987) and also provide managers with a base-line as a goal for restoration (Hobbie et al., 2003).

Unlike many available datasets based on catch records (Smith et al., 2000; Crozier \& Kennedy, 2001; Youngson et al., 2002; Vøllestad et al. 2009), in this study there is a measure of catch effort available in the form of the annual angling club membership for this catchment. Although this metric does not provide a measure of total angling time, it does provide a relative measure of changes in fishing pressure over time. Here we show that the inclusion of this measure of catch effort did not improve the variation in catches explained by year for salmon, and for sea trout and 


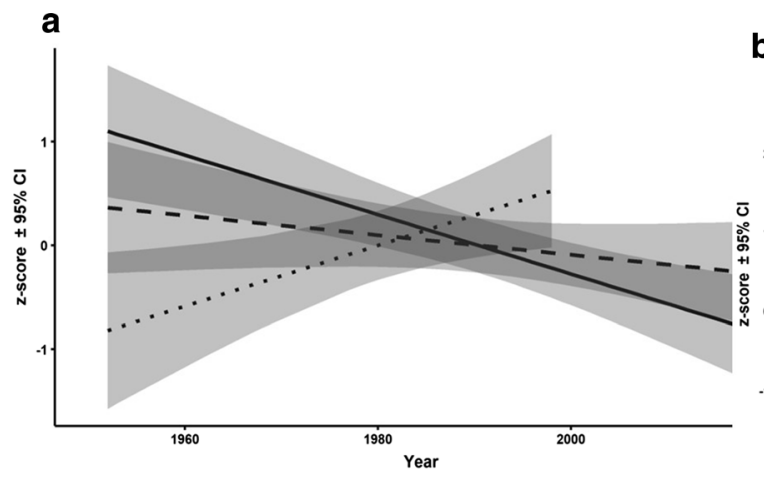

c

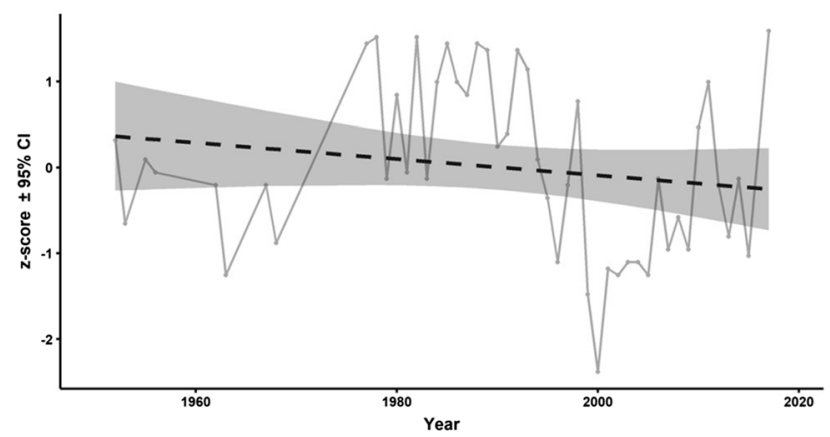

Fig. 7 The standardised annual mass of salmon (solid line), sea trout (dashed line) and brown trout (dotted line) in the Loch Lomond catchment over time. There was a strong effect of year on mean mass overall (a) but that differed between fish groups. The declining mass in (b) salmon, and (c) sea trout did not differ from each other $(P=0.18)$ but both differed from that of

brown trout it did not reliably explain additional variation in any statistically or biologically meaningful way. It is slightly unclear why this would be. Clearly if angling effort were exceedingly high, or exceedingly low, then it is unlikely that effort would not impact catches. It is possible that the interannual variation in effort was simply not of a magnitude to appreciably and detectably, impact catches; alternatively simple angler number may be an inadequate measure of catch effort, as not every angler provides a catch return (although this is a legal requirement). Given this finding however, for the purposes of this study, catches from Loch Lomond were not corrected for angling effort. Fishing catches used as a proxy for population change have the capacity to misrepresent change when hyperstability may be occurring. Hyperstability has been shown to occur when fishing catches remain constant during a period of an underlying

\section{b}

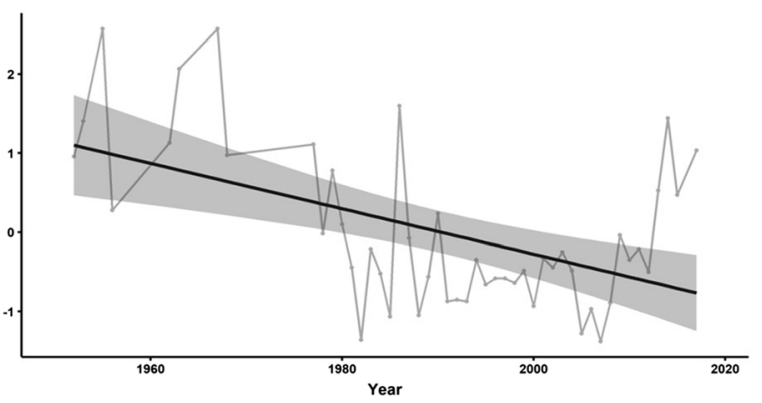

d

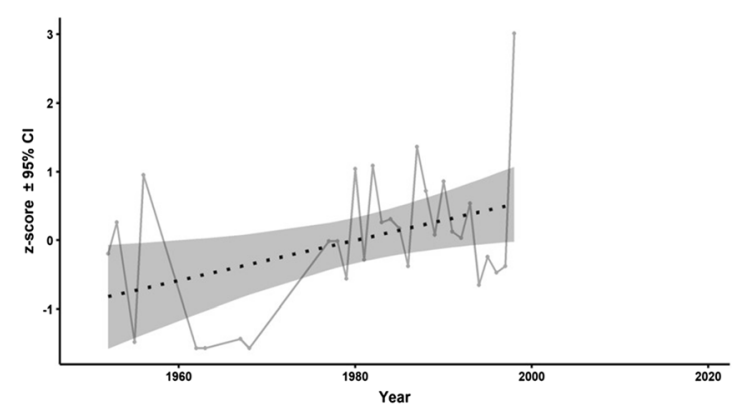

(d) brown trout (cf. salmon: $P<0.001$; cf. sea trout $P<0.022$ ) which showed a generally increase in mass with time (Online Resource Table S2 Model 10). Grey points and the grey solid line are the actual annual mass data on year; grey shading is the 95\% CI around the fitted models

population decline (Hamilton et al., 2016), thus overestimating the true population size. In contrast hyperdepletion is where a rapidly declining fishing catch rate occurs when the underlying population remains stable (Dassow et al., 2020). Given that catches in the study reported here seem to indicate a declining population, if hyperstability is occurring it must be only reducing the magnitude of the identified change in population size. It seems unlikely that the hyperdepletion is having a significant effect as catch size changes, at least for salmon, seem to be consistent with population size change estimated through prefishery abundance measures.

Despite the very considerable inter-annual variation in catches, there is compelling evidence of some general temporal patterns of change in the population size of Atlantic salmon in the Loch Lomond catchment over the period 1903 to 2018. Both a second order 


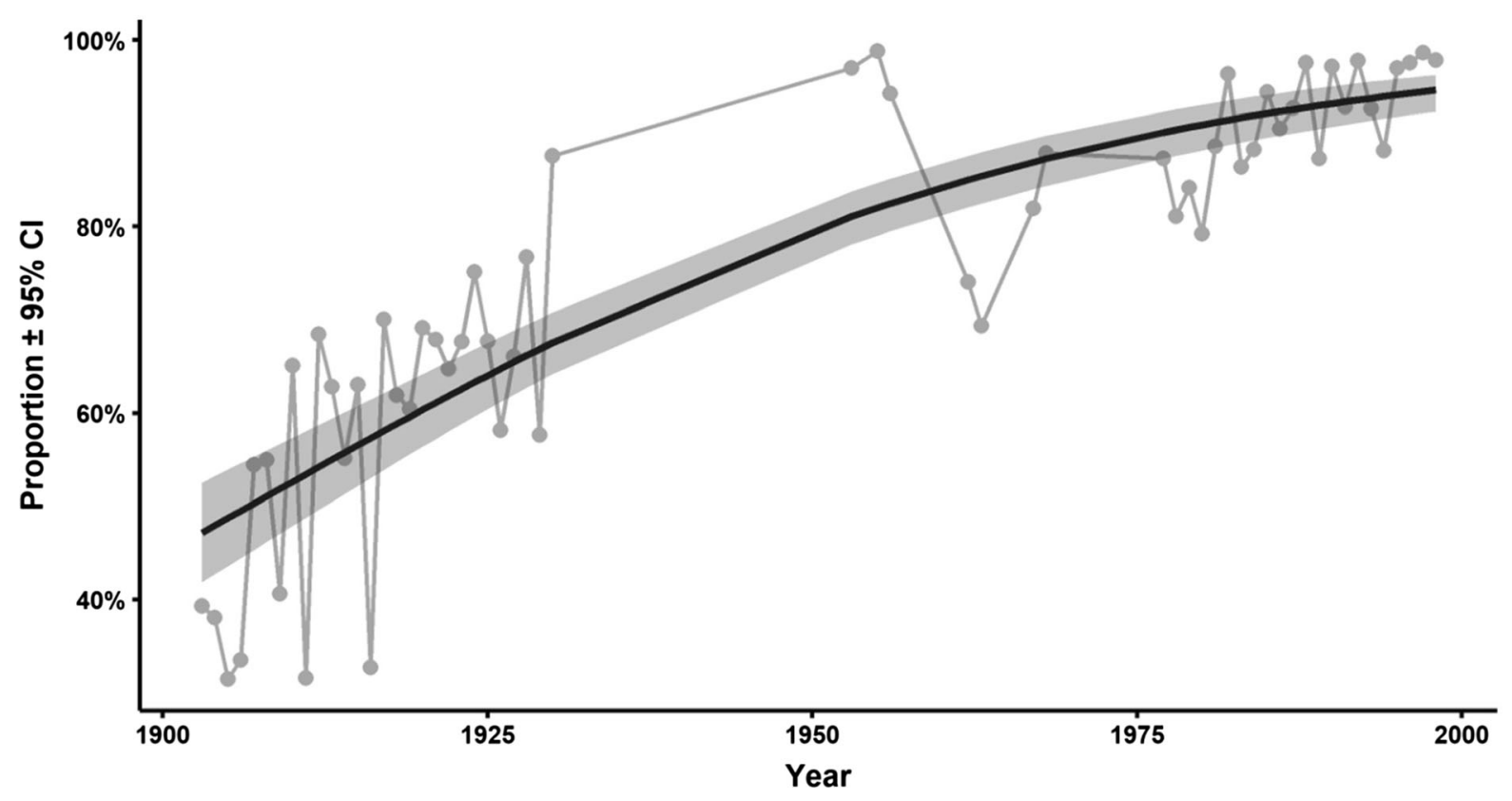

Fig. 8 The proportion of Salmo trutta in catches from Loch Lomond comprising sea trout during the period 1903 to 1998 , increased significantly (Deviance $\left._{(55,56)}=9.508, P<0.001\right)$. The model best describing the change included only Year as an explanatory variable and explained $77.4 \%$ of the variation in

polynomial and a harmonic function included in the best fitting model shows that the direction of population trends changed with time and that there was some cycling in the population, but that year explained a considerable amount of the variation in catch (37\%).

Although with only a shorter time series, it is informative to compare time series patterns in the data from Lomond, with national and international statistics on salmon. Across all countries reporting national statistics to ICES (Canada, USA, Norway, Russia, Iceland, Sweden, Denmark, Finland, Ireland, England, Wales, Scotland, Northern Ireland, France and Spain), year was an exceptionally strong predictor of the change in reported salmon catch (without any measure of catch effort), explaining $92 \%$ of catch variation. Thus between 1960 and 2016, reported salmon catches declined by around $88 \%$ (Fig. 1). Over the period 1971 to 2016, year was a very strong predictor of the ICES estimates of PFA (a measure of salmon population size independent of catches) (ICES, 2019) for the whole of southern Europe (Northern Ireland, England, Wales, Ireland, France, Scotland and south and west Iceland), with year explaining $86 \%$ of the variation in PFA estimates over this time. The change in the PFA the data $\left(R^{2}=0.774\right)$ (Online Resource Table S2 Model 11). Grey points and the solid line are the actual annual proportionate catch data on year; solid dark line is the fitted polynomial model with grey shading the $95 \%$ CI

estimates for Scotland alone between 1971 and 2016 was similarly strongly predicted by year, explaining $79 \%$ of the variation in annual PFA. Models best describing the patterns of change in each of these indicate some evidence of cycles in salmon PFA in both South Europe (13 years) and Scotland (19 years). However, the clearest pattern was that of a declining trend in population across these years; with the South Europe PFA estimate declining by approximately $74 \%$ from 1972 to 2016 and that of Scotland by a very similar and statistically identical magnitude (72\%), over the same period (Fig. 4a). However, this pattern is not replicated in Loch Lomond where the evidence is that the very marked rate of decline in both Scotland and more widely across southern Europe has not occurred in Loch Lomond over this time period.

Notwithstanding that there are clear differences in trends in the salmon population between Lomond and Scotland, and Lomond and south Europe, there are also differences in the observable pattern of trends depending upon the length of the time series. In Loch Lomond there is evidence of a generally increasing trend in the Lomond population in the early years of the data series available for this study, i.e., from the 




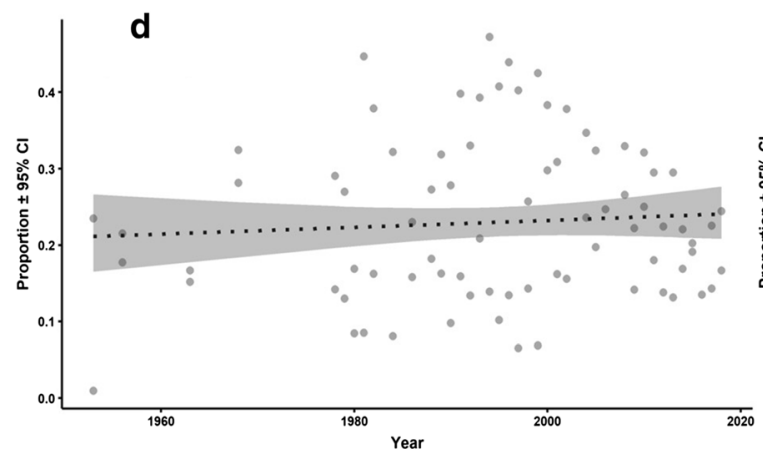

Fig. 9 Between 1953 and 2018, there have been significant patterns of change in the number of salmon caught in four seasons (Deviance $\left._{(359,352)}=27.95, P<0.001\right)(\mathbf{a})$. The best model describing the change included an interaction between Year and Season (Online Resource Table S2 (Model 12)). The regression line explained $59.4 \%$ of the variation in the data
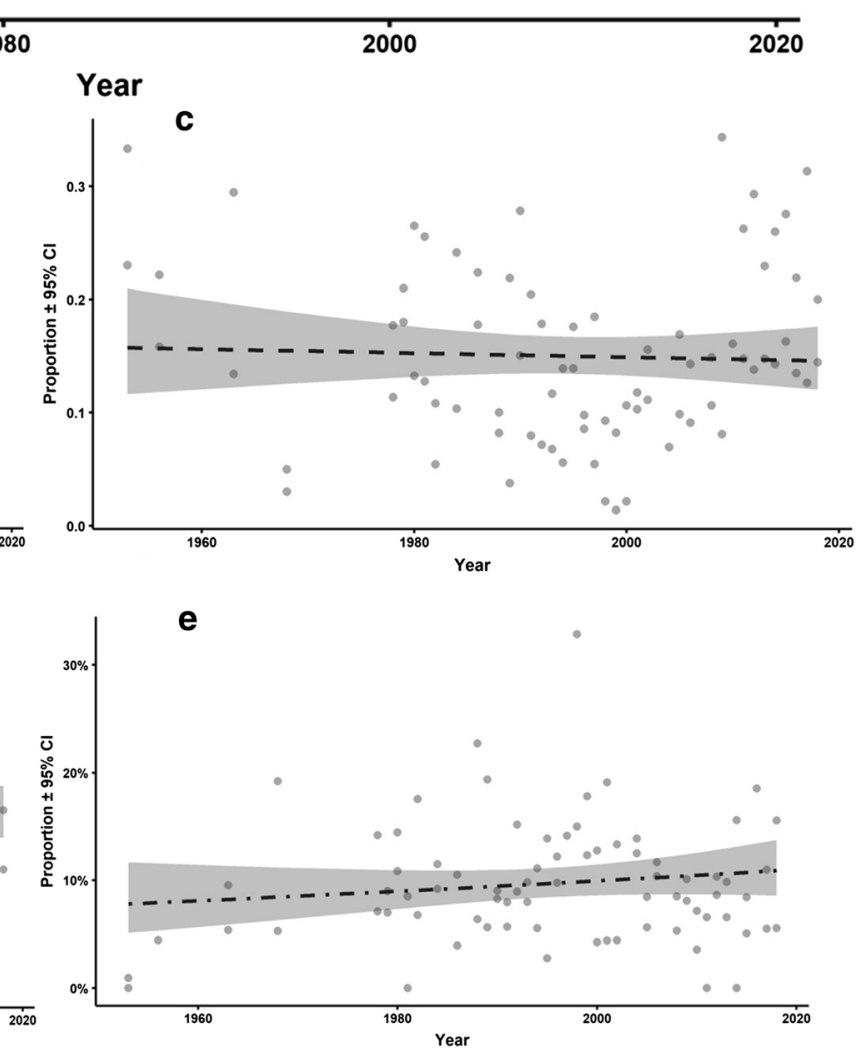

$\left(R^{2}=0.594\right)$. Over the time period, salmon catches in spring (February to April) (b) have declined significantly $(P=0.001)$. In early summer (c), late summer (d) and autumn (e) there was no significant change in salmon catches. Grey points are the actual annual proportionate catch data on year; the line is the fitted polynomial model with grey shading the $95 \%$ CI 
1900's to the mid 1920's (Fig. 2). From the mid 1920 's until the early 1970's the data presented here indicates that the population fluctuated markedly but was generally relatively large, the population then declined again from the 1970's towards the end of the time period, with arguably a small but consistent increase in the 1990's and possibly again following 2015. This pulse of relatively high abundance in the middle of the dataset from Lomond has been shown in other data on Atlantic salmon for which there is a long dataset. Boylan and Adams (2006) present a salmon catch dataset from 1875 to 2001 from the Foyle catchment (Ireland and Northern Ireland) showing two periods of consistently high catches, peaking in the early 1930's and again in the late 1960's, after which catches declined markedly. Friedland et al. (2003) provide landings of North American Atlantic salmon from multiple fisheries from 1910 to 2000 and show similar peaks of abundance in around 1930 and the mid 1970 with population size markedly rising before and fall after these periods.

The sea trout population from Loch Lomond also shows evidence of decline in the period between 1903 and 2018, albeit that the magnitude of change over the period is not large. Although year successfully predicted catches, it only accounted for a relatively small proportion of all variation (26\%), strongly suggesting that interannual catch variation was markedly influenced by drivers other than long-term declines in population size. In contrast, year strongly predicted change in sea trout catches between 1952 and 2018 from rivers draining into the west of Scotland (as does the Loch Lomond catchment), explaining $75 \%$ of variation in catches. For the shorter period when the two datasets overlap (1952-2018) there was no detectable difference in trends of annual proportional abundance of sea trout from Lomond and west Scotland (Fig. 7b) (Moore, 2020), indicating that the Lomond population is tracking the change seen across a much wider geographic area.

Brown trout (here used to denote the non-anadromous component of Salmo trutta population) catches in Loch Lomond also show a rapid change over time. With the catch rate dropping markedly from the beginning of the 1900s into the 1930's, after which there is only modest signs of a very small change in the estimated population size. Year provided a good predictor of the population index provided by catch, explaining $52 \%$ of variation. It is uncertain how reliable the catch data are as an indicator of the brown trout population for which, illogically, there is no statutory requirement for catch returns to be made, whereas there is for the other common life history variant, sea trout, as well as for salmon under the Salmon \& Freshwater Fisheries (Protection) (Scotland) Act 1951. As a result, it is possible that there is less rigour in the collation of data for brown trout compared with sea trout and salmon. However, if that were the case, then for the patterns manifested in the data presented here to emerge, there would have to have been a sequential change over time in the collation of these data.

Interestingly, the pattern of population change was similar for the two anadromous fish groups examined for Loch Lomond, thus the relative abundance of sea trout and salmon were responding similarly over time, the trends of both groups, however, differed from that of brown trout. Unsurprisingly, the Loch Lomond catchment and the fisheries management practices have changed markedly over the 116 year period of this data-set (Dickinson, 1994). How these changes have influenced salmonid populations and their relative magnitude of effect is uncertain but one change which is likely to have had an effect is rainfall which has increased by $75 \%$ over two decades up to the 1990's (Ventura, 1995).

Several long-term trends in the population metrics showed evidence of weak but detectable short-term cyclic patterns of variation; salmon, sea trout and brown trout catches from Lomond showed cycles of 32 years. The PFA for salmon in southern European rivers, for the whole of Scotland and for sea trout on the west coast of Scotland showed cycles of 13, 19 and 18 years, respectively. The average generation period for salmon varies between places but is approximately between 4 and 5 years and for sea trout marginally longer 5-6 years. Thus it is unlikely that the periodicity of the population harmonic cycles is driven directly by cross generational effects. It is more likely that they are the result of some much longer term cycling in broader environmental features that are affecting salmon and sea trout populations. The differences in the periodicity for salmon between regions suggests that either salmon in different areas are responding to different drivers or that the drivers are the same but with different periodicities across different geographic regions. That the three salmonid groups from Lomond share a similar periodicity 
suggests that they are all responding to the same cyclic population drivers. However, this study gives us no more detailed insight into what these drivers might be.

The drivers of decline in salmonid populations are manifold, likely complex and vary between species. The evidence for drivers of change for the two species in this study has been dealt with in a number of studies (see for example Thorstad et al., 2007; Forseth et al., 2017; Nicola et al., 2018; Thorstad \& Finstad, 2018; Moore, 2020) and as this study provides no direct evidence of the mechanisms of the population change described here, we do not speculate further on which may be operating on the populations examined here.

In addition to changes in the population size, there is evidence of changes in a number of life history variables for these three fish groups. The mean mass of both salmon and sea trout in the Lomond fishery declined (by 24\% and 9\%, respectively) between 1952 and 2017. In contrast the mean mass of non-anadromous brown trout caught increased by $92 \%$ over the same period. One possible explanation for the decrease in salmon body size over this period is that the component of the population that comprises multisea winter salmon which are typically larger, have almost certainly declined. This has been described from elsewhere in Scotland (Youngson et al., 2002) and there is evidence of this occurring in Loch Lomond (see below). A similar pattern has also been identified in several Finnish salmon populations in the Baltic Sea area; Kallio-Nyberg and colleagues (Kallio-Nyberg et al., 2020) found that a higher proportion of the population returned as $1 \mathrm{SW}$ salmon between 2001 and 2012 and this was significantly correlated with increasing temperature in the area. The same study also found that even within the $1 \mathrm{SW}$ fish, body size decreased with increasing temperature. The explanation for the apparent increase in body size of resident brown trout is unclear. One possibility may be that faster growth is a density-dependent response to reduced population size; but it is also possible that there has been a change in the recording of this life history group with only large size fish being recorded in later years.

There is evidence from these data of a gradual change in the predominant life history strategy expressed in trout in the Lomond catchment, switching from freshwater residency towards anadromy over the 116 years of this study (Fig. 8). In 1903 around 50\% of all trout reported caught were anadromous (and
$50 \%$ freshwater resident); by 2018 freshwater resident trout comprised less than $10 \%$ of all trout catches. It is possible that this is a real phenomenon and there is some anecdotal evidence that freshwater resident trout are less common than previously. However, this may also be a reporting bias with sea trout being more likely to be reported in catch returns because of the statutory requirement to do so. If the latter explanation were the case, it is difficult to understand why the data would show a gradual change from resident brown trout to sea trout as opposed to a rapid change around 1952. However, the data do not allow us to separate these competing explanations.

The data reported here also provide evidence of change in the timing of migration into freshwater by salmon. There is a marked decline with time in salmon being caught in spring (February, March and April) in any year. Salmon migrating into freshwater early in the year prior to spawning in the following winter, predominately comprise multi-sea-winter fish that have spent two or more winters feeding at sea. They are almost always larger than fish that have spent only one winter at sea that usually migrate into freshwater later in the year. Overall, the proportion of the annual catch in spring (presumed to be mostly multi-seawinter fish) fell from $12 \%$ to less than $2 \%$ between 1903 and 2018 in Loch Lomond. One explanation for this is that the annual pattern of fishing activity has changed over the time series investigated here. We have no evidence available for this effect occurring here, and declines in the multi-sea-winter salmon component of salmon populations have been reported elsewhere in Scotland (Youngson et al., 2002; Todd et al., 2012) and beyond (ICES, 2019), pointing to this being a wider change in migration pattern.

There are a number of conclusions that stem from the study presented here. It is clear that there have been consistent and sustained changes in the salmonid populations of Loch Lomond over the last 12 decades. Thus, null hypothesis 1 is rejected. For sea trout, that change, at least in recent decades, seems to mirror that of wider Scotland. For salmon, the evidence is that the pattern of general decline over the last few decades is very considerably less marked than that of the rest of Scotland and more widely for the rest of southern Europe. This suggests that the Lomond population is buffered from the drivers of population change influencing populations elsewhere. Thus, null hypothesis 2 is rejected but hypothesis 3 is not. Salmon and 
sea trout population trends show a high level of consistency whereas both differ from that of brown trout. Thus, null hypothesis 4 is supported for the two anadromous fish groups but not for non-anadromous brown trout. A measure of angling effort available to this study did not adequately improve explained variation in angler catches; thus, null hypothesis 5 is supported. The pattern of change in salmon and sea trout populations also differs, depending on the time period over which it is examined. A short data series of four decades or so would suggest a pattern of decline. The longer time series of almost 12 decades strongly points to periods of low abundance in the past. One consequence of this is that a management target aimed at achieving a baseline framed around salmonid population sizes in the late 1960's/early1970's (not long after when catch records for salmonids for many catchments in the UK began) is likely an unrealistic and unsustainable goal. This would not be apparent without long time series data.

There is evidence that body size of salmon and sea trout is declining and, related to this, that the component of the salmon population that returns early in the spring before spawning, which are typically larger in size are much less abundant; thus null hypotheses 6 and 8 are rejected. Also, there was strong evidence of changing relative abundance of anadromous sea trout compared to resident brown trout over the time series; thus, null hypothesis 8 is rejected. Taken together it is clear that there is a very strong case of management intervention for the salmonid populations in Loch Lomond specifically and the Scotland more generally.

Acknowledgements We thank the successive executive officers serving on the Loch Lomond Angling Improvement Association, who, over in excess of a century, have collated and retained the data from their fishery that has enabled this analysis. Rowan Smith helped with technical support. Two anonymous referees invested considerable effort to markedly improve an earlier draft of this paper.

Funding This work was supported by the SeaMonitor project supported by EU award IVA5060 from the Interreg 5A programme.

Data availability Data underpinning this paper is either in the public domain or will be made available on reasonable request.

\section{Declarations}

Conflict of interest The authors declare no conflict of interest.

Ethical approval This study was compliant with UK ethical standards.

Open Access This article is licensed under a Creative Commons Attribution 4.0 International License, which permits use, sharing, adaptation, distribution and reproduction in any medium or format, as long as you give appropriate credit to the original author(s) and the source, provide a link to the Creative Commons licence, and indicate if changes were made. The images or other third party material in this article are included in the article's Creative Commons licence, unless indicated otherwise in a credit line to the material. If material is not included in the article's Creative Commons licence and your intended use is not permitted by statutory regulation or exceeds the permitted use, you will need to obtain permission directly from the copyright holder. To view a copy of this licence, visit http://creativecommons.org/licenses/by/4.0/.

\section{References}

Almodóvar, A., D. Ayllón, G. G. Nicola, B. Jonsson \& B. Elvira, 2019. Climate-driven biophysical changes in feeding and breeding environments explain the decline of southernmost European atlantic salmon populations. Canadian Journal of Fisheries and Aquatic Sciences 76: 1581-1595.

Beaumont, W., J. Welton \& M. Ladle, 1991. Comparison of rod catch data with known numbers of Atlantic salmon (Salmo salar L.) recorded by a resistivity fish counter Is a southern chalk stream. In Cowx, I. (ed), Catch Effort Sampling Strategies: Their Application in Freshwater Fisheries Management Fishing News Books, Oxford: 49-60.

Boylan, P. \& C. E. Adams, 2006. The influence of broad scale climatic phenomena on long term trends in Atlantic salmon population size: an example from the River Foyle, Ireland. Journal of Fish Biology 68: 276-283.

Campana, S. E., 1996. Year-class strength and growth rate in young Atlantic cod Gadus morhua. Marine Ecology Progress Series 135: 21-26.

Chaput, G., 2012. Overview of the status of Atlantic salmon (Salmo salar) in the North Atlantic and trends in marine mortality. Marine Science 69: 1538-1548.

Clarke, C. W., 2010. Mathematical Bioeconomics: The Mathematics of Conservation, Wiley, Hoboken:

Condron, A., R. DeConto, R. S. Bradley \& F. Juanes, 2005. Multidecadal North Atlantic climate variability and its effect on North American salmon abundance. Geophysical Research Letters 32: 1-4.

Crozier, W. W. \& G. J. A. Kennedy, 2001. Relationship between freshwater angling catch of Atlantic salmon and stock size in the River Bush, Northern Ireland. Journal of Fish Biology 58: 240-247.

Dassow, C. J., A. J. Ross, O. P. Jensen, G. G. Sass, B. T. van Poorten, C. T. Solomon \& S. E. Jones, 2020. Experimental 
demonstration of catch hyperstability from habitat aggregation, not effort sorting, in a recreational fishery. Canadian Journal of Fisheries and Aquatic Sciences 77: 762-769.

Davidson, I., R. Cove, R. Hillman, P. Elsmere, N. Cook, \& A. Croft, 2017. Observations on sea trout performance in the Rivers Dee, Tamar, Lune \& Tyne (1991-2014). In Harris G (ed) Sea Trout, Science and Management. Matador, Beauchamp: 470-486.

Dickinson, G., 1994. Vegetation and land use in the Loch Lomond catchment. Hydrobiologia 290: 53-61.

Dodds, W. K., C. T. Robinson, E. E. Gaiser, G. J. A. Hansen, H. Powell, J. M. Smith, N. B. Morse, S. L. Johnson, S. V. Gregory, T. Bell, T. K. Kratz \& W. H. McDowell, 2012. Surprises and insights from long-term aquatic data sets and experiments. BioScience 62: 709-721.

Elliot, J., 1987. Population regulation in contrasting populations of trout Salmo trutta in two Lake District streams. Journal of Animal Ecology 56: 83-98.

Elliot, J. \& J. M. Fletcher, 2001. A comparrision of three methods of assessing the abundance of Arcitc charr Salvelinus alpinus in Windermere (northwest England). Fishereis Research 53: 39-46.

Evans, R., \& G. Harris, 2017. The collection of sea trout and salmon statistics from the recreational rod fishery in England and Wales In Harris, G. (ed), Sea Trout, Science and Management. Matador, Beauchamp: 487-506.

Forseth, T., E. B. Thorstad, \& P. Fiske, 2017. Status of wild Atlantic salmon in Norway 2017. Vitenskapedlig Råd For Lakseforvaltning: 1-9.

Franck, R. 1694. Northern Memoirs, Calculated for the Meridian of Scotland. Constable: Edinburgh.

Friedland, K. D., D. G. Reddin \& J. F. Kocik, 1993. Marine survival of North American and European Atlantic salmon: effects of growth and environment. ICES Journal of Marine Science 50: 481-492.

Friedland, K. D., D. G. Reddin, J. R. McMenemy \& K. F. Drinkwater, 2003. Multidecadal trends in North American Atlantic salmon (Salmo salar) stocks and climate trends relevant to juvenile survival. Canadian Journal of Fisheries and Aquatic Sciences 60: 563-583.

Grossman, G. D., R. F. Carline \& T. Wagner, 2017. Population dynamics of brown trout (Salmo trutta) in Spruce Creek Pennsylvania: a quarter-century perspective. Freshwater Biology 62: 1143-1154.

Hamilton, R. J., G. R. Almany, D. Stevens, M. Bode, J. Pita, N. A. Peterson \& J. H. Choat, 2016. Hyperstability masks declines in bumphead parrotfish (Bolbometopon muricatum) populations. Coral Reefs 35: 751-763.

Hobbie, J., S. Carpenter, N. Grimm, J. Gosz \& T. Seastedt, 2003. The US long term ecological research program. BioScience 53: 21 .

Hojesjo, J., D. Aldven, J. Davidsen, S. Pedersen, \& E. Degerman, 2017. Perspectives on sea trout stocks in Sweden, Denmark and Norway: Monitoring threats and management In Harris, G. (ed), Sea Trout Science and Management. Matador, Beauchamp: 442-457.

ICES, 2017. Report of the Working Group on North Atlantic Salmon (WGNAS) 29 March -7 April 2017, ICES, Copenhagen:
ICES, 2019. Report of the Working Group on North Atlantic Salmon (WGNAS). ICES Scientific Reports, 1:16. Copenhagen.

Kallio-Nyberg, I., I. Saloniemi \& M. L. Koljonen, 2020. Increasing temperature associated with increasing grilse proportion and smaller grilse size of Atlantic salmon. Journal of Applied Ichthyology 36: 288-297.

Karjalainen, J., H. Auvinen, H. Helminen, T. J. Marjomäki, T. Niva, J. Sarvala \& M. Viljanen, 2000. Unpredictability of fish recruitment: interannual variation in young-of-the-year abundance. Journal of Fish Biology 56: 837-857.

Lobón-Cerviá, J., 2007. Numerical changes in stream-resident brown trout (Salmo trutta): uncovering the roles of densitydependent and density-independent factors across space and time. Canadian Journal of Fisheries and Aquatic Sciences 64: 1429-1447.

Maitland, P. S., 1972. Loch Lomond: man's effects on the Salmonid Community. Journal of the Fisheries Research Board of Canada 29: 849-860.

Marine Scotland Science, 2019. Salmon and Sea Trout fishery statistics: 2018 Season - reported catch and effort by method. Marine Scotland Science, Montrose.

Moore, I., 2020. Factors impacting sea trout (Salmo trutta) populatons in changing marine environments. $\mathrm{PhD}$ thesis, University of Glasgow: 293pp.

Nicola, G. G., B. Elvira, B. Jonsson, D. Ayllón \& A. Almodóvar, 2018. Local and global climatic drivers of Atlantic salmon decline in southern Europe. Fisheries Research Elsevier 198: 78-85.

Palm, S., L. Laikre, P. E. Jorde \& N. Ryman, 2003. Effective population size and temporal genetic change in stream resident brown trout (Salmo trutta). Conservation Genetics 4: 249-264.

R Development Core Team, 2017. R: A Language and Environment for Statistical Computing, R Foundation for Statistical Computing, Vienna:

Shearer, W., 1988. Relating catch records to stocks. In Mills, D., \& P. D (eds), Atlantic Salmon. Springer, Dordrecht: 256-274.

Shearer, W. M., 1990. The Atlantic salmon (Salmo salar L.) of the North Esk with particular reference to the relationship between both river and sea age and time of return to home waters. Fisheries Research 10: 93-123.

Shelton, A. O. \& M. Mangel, 2011. Fluctuations of fish populations and the magnifying effects of fishing. Proceedings of the National Academy of Sciences of the United States of America 108: 7075-7080.

Smith, B., 2000. Trends in wild adult steelhead (Oncorhynchus mykiss) abundance for snowmelt-driven watersheds of British Columbia in relation to freshwater discharge. Canadian Journal of Fisheries and Aquatic Sciences 57: 285-297.

Smith, B. D., B. R. Ward \& D. W. Welch, 2000. Trends in wild adult steelhead (Oncorhynchus mykiss) abundance in British Columbia as indexed by angler success. Canadian Journal of Fisheries and Aquatic Sciences 57: 225-270.

Thompson, A. A. \& B. D. Mapstone, 2002. Intra- versus interannual variation in counts of reef fishes and interpretations of long-term monitoring studies. Marine Ecology Progress Series 232: 247-257. 
Thorstad, E. B., \& B. Finstad, 2018. Impacts of salmon lice emanating from salmon farms on wild Atlantic salmon and sea trout. NINA Report 1449, Tronheim: 1-22.

Thorstad, E. B., Æ. F. Økland, Æ. B. Finstad, R. Sivertsga \& B. Æ. R. Scott, 2007. Fjord migration and survival of wild and hatchery-reared Atlantic salmon and wild brown trout postsmolts. Hydrobiologia 582: 99-107.

Todd, C. D., K. D. Friedland, J. C. Maclean, B. D. Whyte, I. C. Russell, M. E. Lonergan \& M. B. Morrissey, 2012. Penological and phenotypic changes in Atlantic salmon populatons in response to a changing climate. ICES Journal of Marine Science 69: 1686-1698.

Townsend, C. R., 1989. Population cycles in freshwater fish. Journal of Fish Biology 35: 125-131.

Ventura, A. M. L., 1995. Trends in the pattern and variability of rainfall in the Loch Lomond basin, Scotland. MSc Thesis, University of Glasgow.

Vøllestad, L. A., D. Hirst, J. H. L'Abée-Lund, J. D. Armstrong, J. C. MacLean, A. F. Youngson \& N. Stenseth, 2009. Divergent trends in anadromous salmonid populations in
Norwegian and Scottish rivers. Proceedings of the Royal Society B: Biological Sciences 276: 1021-1027.

Wilfield, I. J., J. M. Fletcher \& J. B. James, 2008. The Arctic charr (Salvelinus alpinus) populatons of Windermere, UK: population trends associated with eutrophication, climate change and increased abundance of roach (Rutilus rutilus). Environmental Biology of Fishes 83: 25-35.

Wolfe, D. A., M. A. Champ, D. A. Flemer \& A. J. Mearns, 1987. Long-term biological data sets: their role in research, monitoring, and management of estuarine and coastal marine systems. Estuaries 10: 181-193.

Youngson, A. F., J. C. MacLean \& R. J. Fryer, 2002. Rod catch trends for early-running MSW salmon in Scottish rivers (1952-1997): Divergence among stock components. ICES Journal of Marine Science 59: 836-849.

Publisher's Note Springer Nature remains neutral with regard to jurisdictional claims in published maps and institutional affiliations. 